\title{
Laugerie-Haute, Dordogne*
}

$\mathrm{T}$

HE famous rock-shelter of Laugerie-Haute, on the right bank of the Vézère in Dordogne, which was discovered by E. Lartet and H. Christy in 1862 and recorded by them as a palæolithic site, and has since been explored in part from time to time by archæologists, was under excavation by $\mathrm{H}$. Hauser when war broke out in 1914. It was acquired by the State on Hauser's conviction of espionage. In 1921, MM. Denis and Élie Peyrony began the systematic excavation of the shelter. It had never previously been examined below the Solutrean and Magdalenian levels. The investigations were carried on at intervals over a period of years, the excavation being completed in 1935. The last four years were devoted to the east end of the shelter, which had not been attacked before.

The shelter is of considerable size. It is 180 metres in length. The greater part, measuring 132 metres, was covered by huge masses of rock, which had fallen from the roof in palæolithic times. Its breadth is 35 metres. The excavations, which have been carried down to bed-rock at a depth varying from $4 \cdot 50$ metres to $5 \cdot 0$ metres, have produced some unexpected results, and have thrown an entirely new light on Aurignacian culture.

A shelter of this size, obviously, would not be occupied in its entirety at one time, nor would the duration of occupation be uniform. On the west side, eight, or counting subdivisions, ten levels were distinguished, while in the excavations at the east end of the shelter, it was found that further developments and a new industry were intercalated.

The lowest level (A) above bed-rock at both extremities of the shelter is archæologically sterile; but on comparative evidence from other sites of the area it is assigned to Aurignacian I. The lowest level of occupation (B) which follows, with the culture of a people descended from Combe Capelle and contemporary with Aurignacian II, is assigned to Perigordian III. On the east side, where B is a prolonged occupation, markedly homogeneous in character, there followed a heavy fall of rock which completely covered this area of the occupation. On the west the fall at this time was slight. An occupation $\left(\mathbf{B}^{\prime}\right)$ of brief duration, but little later than the preceding, then appears in the eastern section. It was brought to an end by a fall of rock (C) distributed generally over the shelter, which was then abandoned for a prolonged period.

On the west side immediately above the sterile level of rock-fall are deposits with bone and flint artefacts (D) belonging to the final phase of the Aurignacian (Aurignacian V). This industry is recorded in the area for the first time. It is probable that the people were descendants of Cro-Magnon. A level virtually sterile $(\mathrm{E})$ is followed by deposits extending to the back of the shelter (G), in which is an industry of archaic (Mousterian) aspect, but with Solutrean tendencies, termed Proto-Solutrean. On the east side, however, following on the sterile level

* Laugerie-Haute, près des Eyzies (Dordogne). Par Denis et flie Peyrony. (Archives de l'Institut de Paléontologie humaine, Mémoire 19.) Pp. $84+7$ plates. (Paris: Masson et Cie., 1938.) 80 francs,
$\mathrm{E}$, there appears an occupation level varying from $0.20 \mathrm{~m}$. to $0.40 \mathrm{~m}$. in depth (F). The culture, which had not previously been recorded anywhere, and is known only from Laugerie-Haute, and that only on the east side, presents an admixture of Aurignacian and Perigordian characters, evolving new forms with a Magdalenian tendency, for which the term ProtoMagdalenian is suggested. It is also put forward, as a tentative suggestion, that the culture may be the result of a fusion of the Combe Capelle and CroMagnon peoples, who, after living in Perigord for some considerable time without intermingling, were forced to unite under pressure from the Solutreans coming in from the east. Above this level is a sterile layer composed of rock-falls, which covered the floor partially only and did not interrupt occupation for more than a brief period. It was followed by the same culture as on the west side $(\mathrm{H})$, a level in which the Proto-Solutrean culture of $\mathrm{G}$ is followed by the Solutrean in three stages distinguished by type implements.

Following on, on the west side, (I) is a Magdalenian culture without harpoons. On the east, however, there are three phases of this culture, though occupation would appear to have been continuous, and further there is, apparently, no break between Solutrean and Magdalenian; but the periodical ejection of refuse from the shelter has made it possible to distinguish the various industrial horizons by sterile layers.

During the Magdalenian occupation, heavy falls of rock from the roof caused the shelter to be abandoned. Its inhabitants migrated lower down the slope to Laugerie-Basse, where the lowest level of occupation is Magdalenian III; while the great shelter of La Madeleine, four kilometres away, higher up the slope, was not occupied until Magdalenian IV.

A passage-way formed between the fall of rock and the wall of the Laugerie-Haute shelter on the east side has, above a layer of rubble and earth $(J)$, an exiguous level (K) in which appear traces of a culture with harpoons having a single row of barbs-Magdalenian V.

From this time onward the shelter was completely abandoned; but there is evidence of Azilian and neolithic settlement on the site.

A remote corner of the shelter on the west side, approached by a narrow passage only, which from its character can have been neither dwelling nor workshop, must have been a temple, a Holy of Holies, probably, of a neighbouring tribe, similar to those of La Mouthe, Font-de-Gaume, and Les Combarelles. It was probably used by the people of Laugerie-Basse. The walls bear engravings and examples of art in the combined technique of engraving and sculpture in relief.

A number of general conclusions are drawn from this evidence, among which may be mentioned that it would now appear that the Perigordian, the Aurignacian, the Proto-Magdalenian and the Magdalenian cultures form a single 'block', into which, in Perigord, the Solutrean intrudes for a certain period of time and then disappears, in so far as the 
culture is concerned. Further, the climate of the Upper Palæolithic would appear not to have been uniform throughout its duration. It was cold in late Mousterian and Perigordian I, glacial in Aurignacian I, and so continuing up to the beginning of Solutrean, when it became milder. It continued to be milder throughout that period and in Magdalenian I-V. It was glacial in Magdalenian V and VI, and milder to temperate from Magdalenian through Azilian, Tardenoisian and neolithic.

\section{Non-Destructive Testing}

$\mathrm{U}^{\mathrm{N}}$ NER the auspices of the Institution of Electrical Engineers, a whole-day discussion was held on non-destructive testing on November 25. Seven introductory papers were arranged for and printed by a new association-the Joint Committee on Materials and their Testing.

The first paper was by Dr. A. P. M. Fleming and Mr. B. G. Churcher, and discussed electrical and magnetic methods. Seeing that modern physics has arrived at the conclusion that fundamentally all matter and all physical phenomena are electrical manifestations, and that electrical and other forms of energy have long been a matter of common experience, it is natural that electrical and magnetic methods of testing materials should be in everyday use. The authors divide these methods into three classes. In the first are included the methods used for measuring the intrinsic electrical and magnetic properties of materials ; in the second, the methods devised for the assessment or detection of a nonelectrical or non-magnetic property or condition by means of electrical or magnetic effects in a material ; finally, they describe the methods in which electricity or magnetism is used indirectly or incidentally in the assessment of a non-electrical or non-magnetic property of a material. In this latter class are included the measurements of dimensions, velocity, acceleration, fluid flow, pressure, temperature, illumination, etc. As these are not methods of testing materials, they have as a rule only been touched upon, but the modern methods of considering the thermal emissivity of surfaces, the specific heats of liquids and solids and the thermal resistivity of materials are specially mentioned. The greatest stress is laid on testing the magnetic properties of ferro-magnetic materials at high and low frequencies, as a knowledge of these is essential to the electrical industry. Various methods are described for detecting flaws or cracks in steel by means of a magnetic powder or by tracing out the lines of force at the surface by a small compass needle.

The second paper was by Dr. R. Berthold (Germany), who describes magnetic and electric devices for bridging the gaps left and overcoming some of the disadvantages which occur with X-ray and radium (gamma radiation) testing. He shows how the magnetic powder can be employed for detecting flaws in castings, worked objects, joints in metals, etc. In these cases the metals tested must be very carefully demagnetized after the test, particularly those to be used in aircraft.

In a paper by Dr. V. E. Pullen, who was the first to start testing metallic structures by X-rays at Woolwich twenty-two years ago, it is stated that radiological testing is incomplete without the use of complementary methods which usually become apparent in the course of the investigation. Illustrations are given of some of the elaborate apparatus used at
Woolwich and of the radiographs that can be obtained by their use. The paper by J. E. de Graaf (Holland) describes industrial radiography as now practised on the continent of Europe. Mobile apparatus is often used in this work. The necessary apparatus is transported in a motor vehicle which houses also the dark room and accessories. About sixteen such installa. tions are in operation on the Continent. There are one or two in Belgium, one in the Netherlands and about thirteen in Germany. The staff per car is composed of two or three men skilled in photographic technique. The results are interpreted by experts, who generally belong to a central body so as to ensure that a uniform standard is maintained.

Dr. Dorey gave an account of acoustic and general methods of non-destructive testing. Perhaps the oldest acoustic method of testing is that of listening to the sound produced by giving an article a sharp blow. It is instinctive on the part of the engineer who doubts the soundness of an article to give it a tap and listen for the ring. The production of a pure note corresponding to the natural frequency of vibration of the article may be taken as evidence that the article is sound and free from serious defects. A refinement of this method has recently been effected by the use of an ordinary medical stethoscope. For the testing of structural welds, a rubber cap is fitted over the searching end of the stethoscope, which is then placed against the welded plate whilst the weld under examination is tapped with a hammer. A high-pitched reedy sound occurring in the primary period of sound caused by the hammer blow indicates the presence of defects in the weld. So far this method has not been very successfully developed in Great Britain.

One of the most interesting and valuable methods of non-destructive testing has been in the design of objective noise meters. This work has been carried out in the National Physical Laboratory. The instruments are of the microphone-amplifier-meter type which have been adjusted for measuring the equivalent loudness of noise. Architects and building contractors now pay great attention to the acoustic properties of the materials used for walls, ceilings and floors. The tests are usually carried out by reverberation methods, and the sound-absorption coefficients are calculated from the period of reverberation of the chamber. Hydraulic tests are widely used in industry for proof-testing of pipes and hollow containers.

Dr. F. Förster and Prof. W. Köster (Germany) described a new apparatus for measuring the modulus of elasticity and the damping capacity of a material. They point out that the damping and the modulus of elasticity are quantities which, in contrast to many other technical values, possess an exact physical meaning. 